\title{
Analysis of Long Non-Coding RNA Expression of Lymphatic Endothelial Cells in Response to Type 2 Diabetes
}

\author{
Min Qia Qiuhong Zhou ${ }^{b}$ Weiqi Zeng ${ }^{c}$ Minxue Shenc Xiaomin Liu ${ }^{b}$ Chang Luo \\ Jing Long ${ }^{c}$ Wangqing Chen ${ }^{c}$ Siyu Yanc Jianglin Zhang ${ }^{c}$ \\ aDepartment of Plastic Surgery, ${ }^{b}$ Department of Endocrinology, 'Department of Dermatology, Xiangya \\ Hospital, Central South University, Changsha, China
}

\section{Key Words}

Lymphatic endothelial cells $•$ Type 2 diabetes $•$ Long non-coding RNA • H19

\begin{abstract}
Background: Recent evidence has indicated that long non-coding RNA (IncRNA) is involved in the pathogenesis of type 2 diabetes, but nothing is known about IncRNA expression changes of lymphatic endothelial cells in response to type 2 diabetes. Methods: The GSE38396 dataset was downloaded from the Gene Expression Omnibus database and the probe sets of Human Gnome U133 Plus2.0 microarray were annotated for IncRNA. Differentially expressed IncRNAs between diabetic and non-diabetic lymphatic endothelial cells were calculated. Results: Compared with lymphatic endothelial cells in non-diabetic patients, 31 IncRNAs were downregulated and 79 IncRNAs were up-regualted in lymphatic endothelial cells of type 2 diabetic patients. Several known IncRNAs were found, such as H19, GAS5, UCA1, CRNDE, GAS5, and LINC00312. Co-expression network of differentially expressed IncRNAs and mRNAs were constructed. Based on genomic regions of these IncRNAs, we found that binding sites of MAF and TCF3 were enriched and these IncRNAs may be related to insulin reporter signaling pathway and response to insulin stimulus. Conclusions: In a word, we found a set of IncRNAs were differentially expressed in lymphatic endothelial cells in response to type 2 diabetes and these IncRNAs may be involved in the pathogenesis of diabetes-related complications.
\end{abstract}

\section{Introduction}

The incidence of type 2 diabetes has been rapidly increasing worldwide [1]. Type 2 diabetes is a complex endocrine and metabolic disorder and leads to significant adverse effects to human health. Diabetes impairs the quality of life of many people mainly thorough the cardiovascular complications [2,3]. Dysfunction of endothelial cells is crucial for the pathogenesis of diabetic vascular diseases $[4,5]$. 
In mammals, there are two specialized vascular systems: the blood vasculature and the lymphatic vasculature and these two networks are highly related [6]. Type 2 diabetes leads to microvascular lesions and causes ischemia [7]. The blood vascular endothelial cells show imbalances of secretion of pro- and anti-inflammatory cytokines and increased prothrombotic activity [8]. However, little is known about the involvement of lymphatic endothelial cells in human type 2 diabetes.

Long non-coding RNAs (lncRNA) was considered as "transcription noise", but mounting papers have demonstrated that IncRNA transcripts are widely involved in almost every aspects of cell biological function, such as cell differentiation, metabolism, and apoptosis $[9,10]$. Also, recent evidence has proved that lncRNA are also important for the biological function of endothelial cells and lncRNA expression profile is altered in response to stimulus or hyperglycemia in endothelial cells [10-14]. But nothing is known about the lncRNA profile alteration of lymphatic endothelial cells in type 2 diabetes $[15,16]$.

In this article we reported dysregulation of many lncRNAs, including H19, CRNDE, and TUG1 in lymphatic endothelial cells in human type 2 diabetes. It is predicted by bioinformatics methods that these altered lncRNA may be involved in the response to insulin stimulus.

\section{Materials and Methods}

Processing of Lymphatic endothelial cells

The detailed methods were described by Haemmerle M [17]. Briefly, skin samples ( $\mathrm{n}=4$ in each group) were taken from the proximal region of amputated legs or abdominoplastic tissue, and care was taken to excise areas at maximal distance from inflammatory or ulcerous changes $(15 \mathrm{~cm})$. Then, human skin was dermatomized and epidermis and dermis dislocated by incubation in dispase solution. Lymphatic endothelial cells were labeled and isolated with antibodies in a three-step procedure. Total RNA of lymphatic endothelial cells were extracted and amplified and then hybridized to Affymetrix Human Genome U133 (HGU133) Plus 2.0 arrays.

\section{Microarray data processing}

The raw microarray data was downloaded from the gene expression omnibus (GEO) database and this dataset could be accessed by the accession number GSE38396. In accordance with Haemmerle M [17], the raw files of first normalized using the log scale robust multi-array analysis with default settings. After normalization, expression value of each probe was obtained. And differentially expressed probe sets between diabetic vs. non-diabetic lymphatic endothelial cells were calculated using significant analysis of microarray software. $\mathrm{P}<0.05$ was considered as statistically significant. Heatmap of differentially expressed IncRNAs was generated by Cluster (V3.0) software.

\section{LncRNA annotation}

The HGU133 Plus2.0 microarray was used in this study and this array is widely used by numerous researchers in almost every kind of human tissues or cells. the HG U133 plus2.0 array has been annotated for lncRNA to probe lncRNA expression in cancers. In this study, we used the annotation by Zhang X [18]. Only probes that were annotated as IncRNA were selected and transcript ID, chromosome location, strand, biologic types, and other annotation information were also downloaded.

\section{LncRNA-mRNA co-expression network}

We built IncRNA-mRNA-network to identify the interactions between mRNA and IncRNA. LncRNAmRNA network was built according to the normalized signal intensity of specific expression of mRNA and IncRNA. For each pair of mRNA-IncRNA, mRNA-mRNA or IncRNA-lncRNA, we calculated the Pearson correlation and choose the significant correlation pairs $(\mathrm{P}<0.05)$ with which to construct the network.

Genomic Regions Enrichment of Annotations Tool (GREAT)

GREAT assigns biological meaning to a set of non-coding genomic regions by analyzing the annotations of the nearby genes. Thus, it is particularly useful in studying cis functions of sets of non-coding genomic 


\section{Cellular Physiology Cell Physiol Biochem 2017;41:466-474

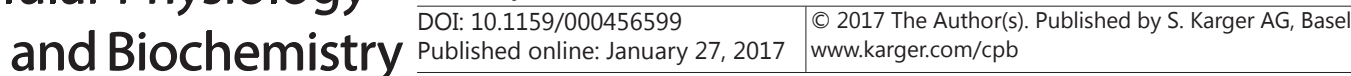 \\ Qi et al.: IncRNA in Lymphatic Endothelial Cells}

regions. GREAT analyses were performed by chromosome location of the differentially expressed IncRNAs and the website (http://bejerano.stanford.edu/great/public/html/) [19].

\section{Results}

\section{Baseline of microarray data}

The Gene Expression Omnibus (GEO) database was searched to identify available dataset. After careful searching and validation, the GSE38396 dataset was selected and analyzed [17]. Data analysis pipeline was shown in Figure 1. Raw data of 8 samples (4 diabetic and 4 non-diabetic lymphatic endothelial cell samples, sample ID: GSM941220-GSM941228) were downloaded from the GEO database. Primary quality of the 8 microarrays was assessed by normalized unscaled standard error (NUSE) algorithm and we found that most boxplots of NUSE values were centered around 1, indicating high quality of the microarray data, except for GSM941227 (Fig. 1A). In addition, Relative Log Expression (RLE) analysis also suggests that the GSM941227 sample varied greatly from the other samples. Thus, GSM941227 was excluded from analysis. and 7 samples ( 4 type 2 diabetes and 3 non-diabetes) were analyzed.

After annotation and statistical analyses, 110 differentially expressed lncRNAs (31 down-regulated and 79 up-regualted) between diabetic and non-diabetic lymphatic endothelial cells were found. Full lists of the 110 lncRNAs were shown in Table 1. Among the 110 lncRNAs, PAX8-AS1 was mostly up-regualted and H19 was mostly down-regulated. As

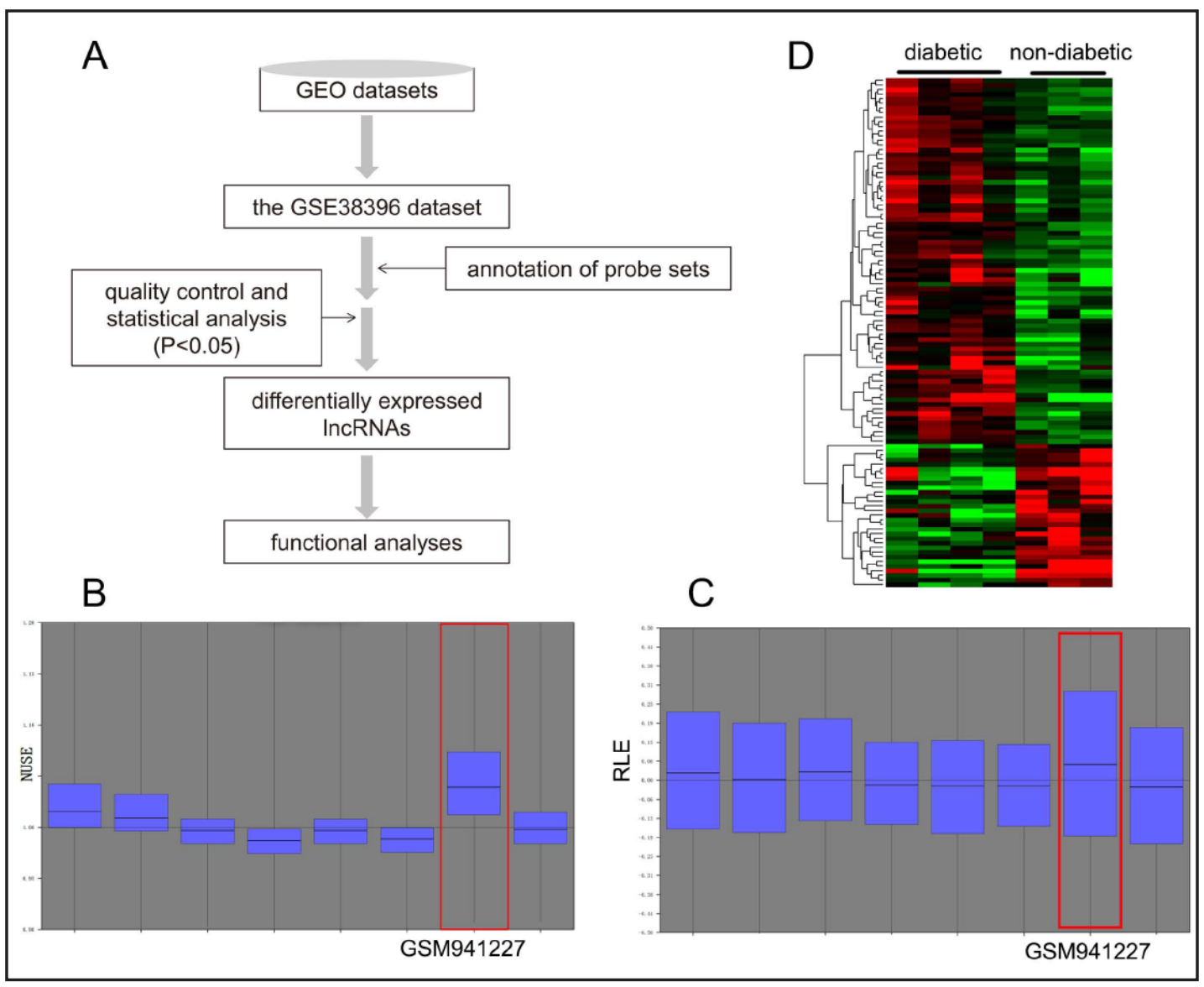

Fig. 1. Analysis of the GSE38396 dataset. The data analysis flow diagram of current study (A); quality of microarrays were assessed by normalized unscaled standard error (NUSE, B) and relative log expression (RLE, C) methods. Heatmap of the 110 differentially expressed lncRNAs were shown (D).

\section{KARGER}


Table 1. Differentially expressed lncRNAs between diabetic and non-diabetic lymphatic endothelial cells. FC: fold change

reported, the IncRNA H19 is closely related with diabetes and glucose metabolism. [20-22] Several known lncRNAs were found, such as GAS5, UCA1,CRNDE, GAS5,LINC00312.

\section{Co-expression Network}

It is proposed that genes with the same biological function or regulated the same pathway way have similar expression patterns. Thus, co-expression network may provide information about function of lncRNAs and co-expression network has been used to predict IncRNA function by many researchers. We built IncRNA-mRNA co-expression network with statistically differentially expressed lncRNA and mRNA (Fig. 2A). Among the network, we found 4 lncRNAs ENSG00000245694 (CRNDE), NR_027012 (LINC00293), NR_015369 (NR2F1-AS1), and ENSG00000230844 (ZNF674AS1) had highest degrees. Then, sub-networks of the 4 IncRNAs were extracted and the 4 lncRNAs were co-expressed with distinctive gene sets (Fig. 2B).

Genomic Regions Enrichment of Annotations Tool (GREAT) analysis

Recent researches have characterized function of many lncRNAs, however the function of most lncRNAs were still unknown. To predict function of the differentially expressed lncRNAs between diabetic and non-diabetic lymphatic endothelial cells, we performed the GREAT analysis based on genomic location of these lncRNAs [19]. As shown, most of these IncRNAs were located nearby transcription start site (Fig.

\begin{tabular}{|c|c|c|c|c|c|}
\hline Accession ID & $\log F \mathrm{C}$ & Chr Name & Gene Start & Gene End & Strand \\
\hline NR_024582 & -0.36 & $\mathrm{X}$ & 73944328 & 74070408 & 1 \\
\hline NR_026956 & -0.69 & 19 & 19756371 & 19776413 & -1 \\
\hline NR_023925 & 0.45 & 18 & 1268311 & 1359629 & -1 \\
\hline NR_026646 & 0.35 & 15 & 24558152 & 24587779 & 1 \\
\hline NR_120317 & 0.45 & 15 & 80195484 & 80252213 & -1 \\
\hline NR_002717 & 0.56 & 13 & 70107213 & 70139753 & 1 \\
\hline NR_026928 & 0.46 & 13 & 32504506 & 32509395 & -1 \\
\hline NR_028138 & -1.01 & 12 & 89708955 & 89711952 & 1 \\
\hline NR_026932 & 0.92 & 10 & 110868890 & 110870904 & -1 \\
\hline NR_027012 & -0.48 & 8 & 46840886 & 46855785 & 1 \\
\hline NR_015364 & 0.50 & 7 & 26486668 & 26496367 & 1 \\
\hline NR_028390 & 0.33 & 6 & 163309985 & 163324530 & -1 \\
\hline NR_027117 & 0.35 & 6 & 35726762 & 35736947 & -1 \\
\hline NR_015369 & 0.50 & 5 & 93541872 & 93581320 & -1 \\
\hline NR_034127 & -0.56 & 5 & 43065187 & 43066971 & -1 \\
\hline NR_040005 & -1.45 & 3 & 75672281 & 75679303 & 1 \\
\hline NR_024065 & -0.86 & 3 & 8571782 & 8574668 & 1 \\
\hline NR_024606 & 0.63 & 2 & 74502617 & 74505065 & 1 \\
\hline NR_024124 & 0.76 & 1 & 116392865 & 116418622 & -1 \\
\hline NR_033998 & -0.61 & 1 & 94928028 & 94963270 & 1 \\
\hline NR_033887 & 0.45 & 1 & 20359801 & 20428794 & -1 \\
\hline NR_002578 & 0.72 & 1 & 173863901 & 173867987 & -1 \\
\hline ENSG00000260386 & 0.48 & 1 & 31500085 & 31508566 & 1 \\
\hline ENSG00000241732 & -2.03 & $\mathrm{~N} / \mathrm{A}$ & $\mathrm{N} / \mathrm{A}$ & $\mathrm{N} / \mathrm{A}$ & N/A \\
\hline NR_015368 & 1.08 & $\mathrm{~N} / \mathrm{A}$ & $\mathrm{N} / \mathrm{A}$ & $\mathrm{N} / \mathrm{A}$ & $\mathrm{N} / \mathrm{A}$ \\
\hline ENSG00000205662 & -1.03 & N/A & $\mathrm{N} / \mathrm{A}$ & $\mathrm{N} / \mathrm{A}$ & $\mathrm{N} / \mathrm{A}$ \\
\hline ENSG00000223482 & 0.62 & N/A & $\mathrm{N} / \mathrm{A}$ & $\mathrm{N} / \mathrm{A}$ & $\mathrm{N} / \mathrm{A}$ \\
\hline ENSG00000246025 & 0.41 & N/A & $\mathrm{N} / \mathrm{A}$ & $\mathrm{N} / \mathrm{A}$ & $\mathrm{N} / \mathrm{A}$ \\
\hline ENSG00000224619 & 0.40 & N/A & $\mathrm{N} / \mathrm{A}$ & $\mathrm{N} / \mathrm{A}$ & $\mathrm{N} / \mathrm{A}$ \\
\hline ENSG00000245443 & 0.58 & N/A & $\mathrm{N} / \mathrm{A}$ & $\mathrm{N} / \mathrm{A}$ & $\mathrm{N} / \mathrm{A}$ \\
\hline ENSG00000247445 & 0.87 & N/A & $\mathrm{N} / \mathrm{A}$ & $\mathrm{N} / \mathrm{A}$ & $\mathrm{N} / \mathrm{A}$ \\
\hline ENSG00000233165 & -0.51 & N/A & N/A & $\mathrm{N} / \mathrm{A}$ & $\mathrm{N} / \mathrm{A}$ \\
\hline ENSG00000237697 & -1.01 & N/A & $\mathrm{N} / \mathrm{A}$ & $\mathrm{N} / \mathrm{A}$ & $\mathrm{N} / \mathrm{A}$ \\
\hline ENSG00000226906 & 0.52 & $\mathrm{~N} / \mathrm{A}$ & $\mathrm{N} / \mathrm{A}$ & $\mathrm{N} / \mathrm{A}$ & $\mathrm{N} / \mathrm{A}$ \\
\hline ENSG00000215560 & 0.41 & $\mathrm{Y}$ & 22296798 & 22298876 & -1 \\
\hline ENSG00000230844 & -0.50 & $\mathrm{x}$ & 46545493 & 46548408 & 1 \\
\hline ENSG00000234405 & 0.40 & $\mathrm{x}$ & 103497523 & 103500317 & 1 \\
\hline ENSG00000228839 & -0.54 & 22 & 31292499 & 31338021 & 1 \\
\hline ENSG00000234883 & 1.02 & 21 & 25561909 & 25575168 & 1 \\
\hline ENSG00000237282 & 0.55 & 20 & 18379049 & 18381484 & 1 \\
\hline ENSG00000213753 & -0.64 & 19 & 58573503 & 58599801 & 1 \\
\hline ENSG00000214049 & 0.42 & 19 & 15828961 & 15836320 & 1 \\
\hline ENSG00000268658 & 0.44 & 19 & 21483374 & 21503238 & 1 \\
\hline ENSG00000227274 & 0.44 & 17 & 12671862 & 12706135 & -1 \\
\hline ENSG00000179859 & -0.85 & 17 & 7913324 & 7915953 & -1 \\
\hline ENSG00000249383 & 0.36 & 17 & 51312609 & 51335165 & -1 \\
\hline ENSG00000245694 & -1.01 & 16 & 54918863 & 54929189 & -1 \\
\hline ENSG00000245694 & -1.43 & 16 & 54918863 & 54929189 & -1 \\
\hline
\end{tabular}

continued 
3A). In addition, several transcription factors (TFs) that are critical for the pathogenesis of diabetes, like MAF, FOX3 were enriched among these genomic regions (Fig. 3) [23, 24]. The enrichment indicated that these TFs might bind to these regions and promote expression of lncRNAs located in these regions. In addition, GREAT analysis also showed that many biological processes were enriched and some were closely related to diabetes, such as "positive regulation of insulin receptor signaling pathway", "regulation of glycogen biosynthetic process", and "response to insulin stimulus" (Fig. 3). Enrichment of these biological processes indicated that in lymphatic endothelial cells IncRNA may be involved in the response to insulin and pathological processes of diabetes.

\section{Discussion}

LncRNA are a kind of RNA molecules that are larger than 200nt and without protein-coding capacity. Due to advances of high-throughput technology like microarray and the next-generation RNA sequencing (RNA-seq), the functional roles of IncRNA have been discovered [25, 26]. The expression profiles of lncRNA have been characterized in many diseases by microarray and RNA-seq. recently, researchers have demonstrated that annotation of published microarray data is a feasible and reliable method to profile IncRNA expression $[27,28]$. In the current study, we re-annotate the HG U133Plus2.0 microarrays and analyzed IncRNA expression profile of lymphatic endothelial cells in diabetic and non-diabetic patients. We found many lncRNAs were differentially expressed in response to type

\begin{tabular}{|c|c|c|c|c|c|}
\hline Accession ID & $\log \mathrm{FC}$ & Chr Name & Gene Start & Gene End & Strand \\
\hline ENSG00000247324 & 0.49 & 16 & 71462278 & 71465941 & 1 \\
\hline ENSG00000245750 & 0.42 & 15 & 69463026 & 69571440 & 1 \\
\hline ENSG00000251533 & 0.47 & 14 & 103187221 & 103189028 & -1 \\
\hline ENSG00000233208 & 0.41 & 14 & 90455230 & 90458905 & 1 \\
\hline ENSG00000226722 & 0.40 & 13 & 21872770 & 21878160 & -1 \\
\hline ENSG00000236036 & 0.36 & 13 & 35697524 & 35699256 & 1 \\
\hline ENSG00000261057 & 0.37 & 13 & 102589372 & 102589813 & -1 \\
\hline ENSG00000130600 & -2.21 & 11 & 1995163 & 2001470 & -1 \\
\hline ENSG00000130600 & -1.92 & 11 & 1995163 & 2001470 & -1 \\
\hline ENSG00000226900 & 0.46 & 10 & 132511626 & 132518191 & -1 \\
\hline ENSG00000225768 & 0.40 & 10 & 104474939 & 104480274 & -1 \\
\hline ENSG00000224596 & 0.43 & 10 & 78943328 & 79067895 & -1 \\
\hline ENSG00000235387 & 1.37 & 9 & 35909483 & 35911686 & 1 \\
\hline ENSG00000227388 & -0.51 & 9 & 35772163 & 35790432 & 1 \\
\hline ENSG00000227619 & 0.41 & 9 & 129575409 & 129584556 & 1 \\
\hline ENSG00000235659 & 0.40 & 9 & 61865755 & 61866965 & -1 \\
\hline ENSG00000254129 & 0.43 & 8 & 29110573 & 29140729 & 1 \\
\hline ENSG00000226869 & 0.57 & 7 & 104738597 & 104804107 & -1 \\
\hline ENSG00000179406 & 0.70 & 7 & 66376044 & 66401338 & -1 \\
\hline ENSG00000228775 & 0.68 & 7 & 141704338 & 141738346 & -1 \\
\hline ENSG00000188185 & 0.43 & 7 & 39733632 & 39793092 & 1 \\
\hline ENSG00000188185 & 0.80 & 7 & 39733632 & 39793092 & 1 \\
\hline ENSG00000238033 & 0.35 & 7 & 22649960 & 22665533 & -1 \\
\hline ENSG00000244158 & 0.92 & 6 & 116460739 & 116463692 & -1 \\
\hline ENSG00000230910 & 0.38 & 6 & 68629962 & 68635027 & -1 \\
\hline ENSG00000226249 & 0.40 & 6 & 147741434 & 147743324 & -1 \\
\hline ENSG00000246214 & 0.37 & 5 & 16615926 & 16629969 & 1 \\
\hline ENSG00000253955 & 0.34 & 5 & 173579643 & 173585068 & 1 \\
\hline ENSG00000251603 & -0.66 & 4 & 151667224 & 151670502 & 1 \\
\hline ENSG00000249001 & 0.43 & 4 & 87568035 & 87733956 & -1 \\
\hline ENSG00000248339 & 0.38 & 4 & 171289475 & 171298267 & -1 \\
\hline ENSG00000240024 & 1.17 & 3 & 183447608 & 183456013 & 1 \\
\hline ENSG00000239508 & 0.55 & 3 & 155449184 & 155457753 & 1 \\
\hline ENSG00000171658 & -0.43 & 3 & 185959943 & 185980872 & 1 \\
\hline ENSG00000244161 & 0.37 & 3 & 58162547 & 58170636 & -1 \\
\hline ENSG00000239513 & 0.39 & 3 & 137771949 & 137780878 & 1 \\
\hline ENSG00000235947 & -0.97 & 3 & 4749192 & 4751590 & -1 \\
\hline ENSG00000242516 & -1.96 & 3 & 75672391 & 75679303 & 1 \\
\hline ENSG00000241163 & -0.35 & 3 & 72035300 & 72279503 & -1 \\
\hline ENSG00000226383 & -0.58 & 2 & 156011617 & 156024613 & -1 \\
\hline ENSG00000189223 & 1.35 & 2 & 113211522 & 113276581 & 1 \\
\hline ENSG00000229494 & 0.51 & 2 & 78088730 & 78127806 & 1 \\
\hline ENSG00000189223 & 1.39 & 2 & 113211522 & 113276581 & 1 \\
\hline ENSG00000228203 & 0.83 & 2 & 6912277 & 6918709 & -1 \\
\hline ENSG00000178836 & 0.43 & 2 & 233754305 & 233755345 & -1 \\
\hline ENSG00000230002 & -0.63 & 2 & 73456764 & 73459484 & 1 \\
\hline ENSG00000203643 & 0.39 & 2 & 11721619 & 11724222 & -1 \\
\hline ENSG00000233729 & 0.35 & 2 & 132915557 & 132931494 & 1 \\
\hline ENSG00000237638 & 0.37 & 2 & 64901840 & 64905137 & -1 \\
\hline ENSG00000232931 & 0.40 & 2 & 95807118 & 95816215 & -1 \\
\hline ENSG00000224699 & 0.74 & 1 & 110347116 & 110443817 & 1 \\
\hline
\end{tabular}

continued 
Qi et al.: IncRNA in Lymphatic Endothelial Cells

\begin{tabular}{llllll}
\hline Accession ID & logFC & Chr Name & Gene Start & Gene End & Strand \\
\hline ENSG00000224702 & 0.46 & 1 & 165210627 & 165213090 & 1 \\
ENSG00000224818 & -0.59 & 1 & 201464383 & 201465146 & -1 \\
ENSG00000237463 & 0.38 & 1 & 165476841 & 165582155 & -1 \\
ENSG00000237058 & 0.49 & 1 & 2632568 & 2636620 & 1 \\
ENSG00000203288 & 0.31 & 1 & 151790804 & 151794402 & 1 \\
ENSG00000233184 & 0.87 & 1 & 101025878 & 101087268 & 1 \\
ENSG00000186056 & -0.75 & 1 & 30718504 & 30726827 & 1 \\
ENSG00000244020 & -1.39 & 1 & 237004103 & 237004418 & -1 \\
ENSG00000233410 & 0.38 & 1 & 199006040 & 199021037 & -1 \\
ENSG00000231814 & 0.33 & 1 & 217892900 & 217920804 & 1 \\
ENSG00000228127 & 0.45 & 1 & 115919350 & 115931561 & 1 \\
\hline
\end{tabular}

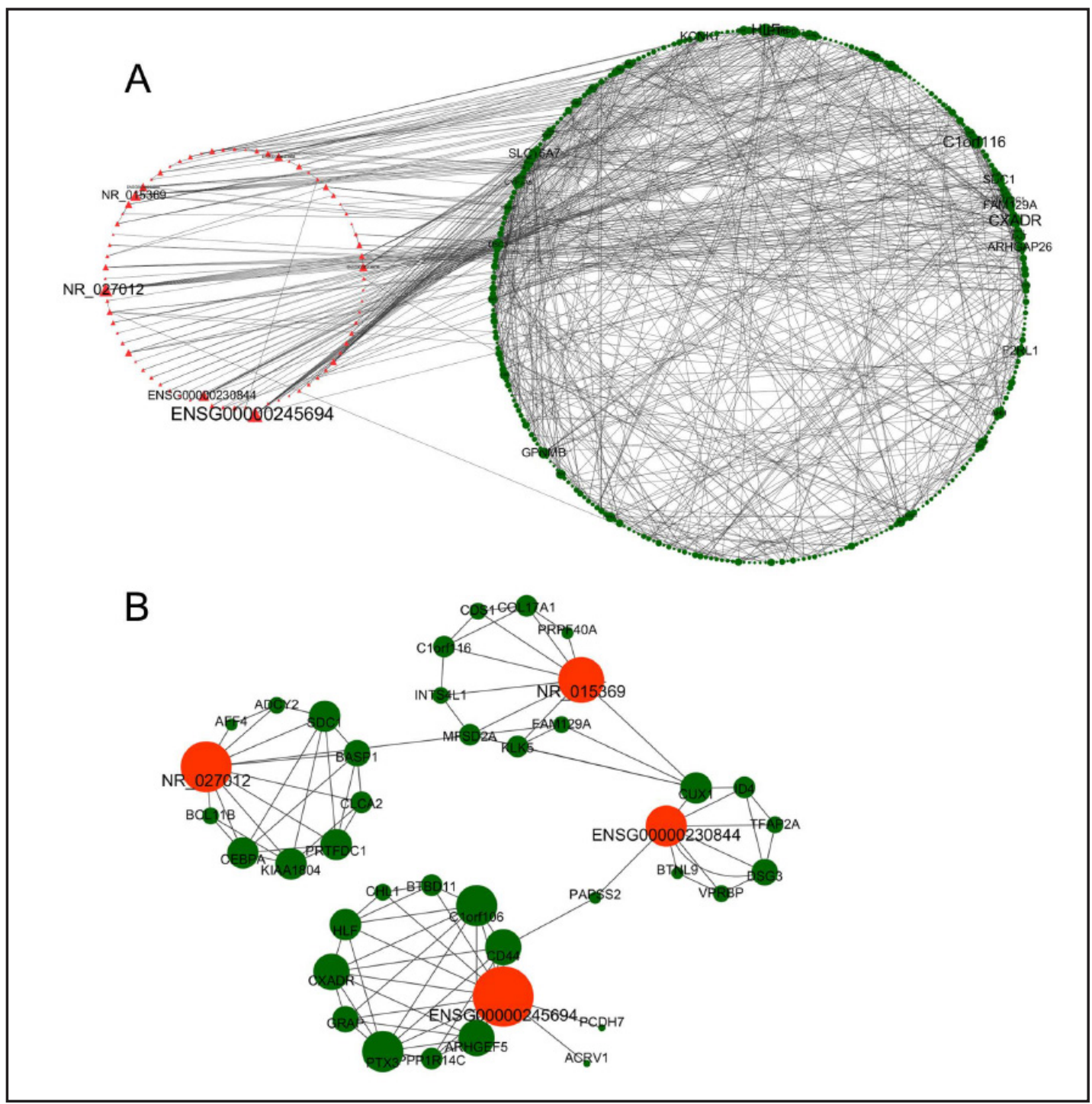

Fig. 2. Co-expression between differentially expressed IncRNAs and mRNAs (A); subnetwork of ENSG00000245694 (CRNDE), NR_027012 (LINC00293), NR_015369 (NR2F1-AS1), and ENSG00000230844 (ZNF674-AS1) (B).

2 diabetes and functional analyses suggested these lncRNAs were involved in response to insulin stimulus. 


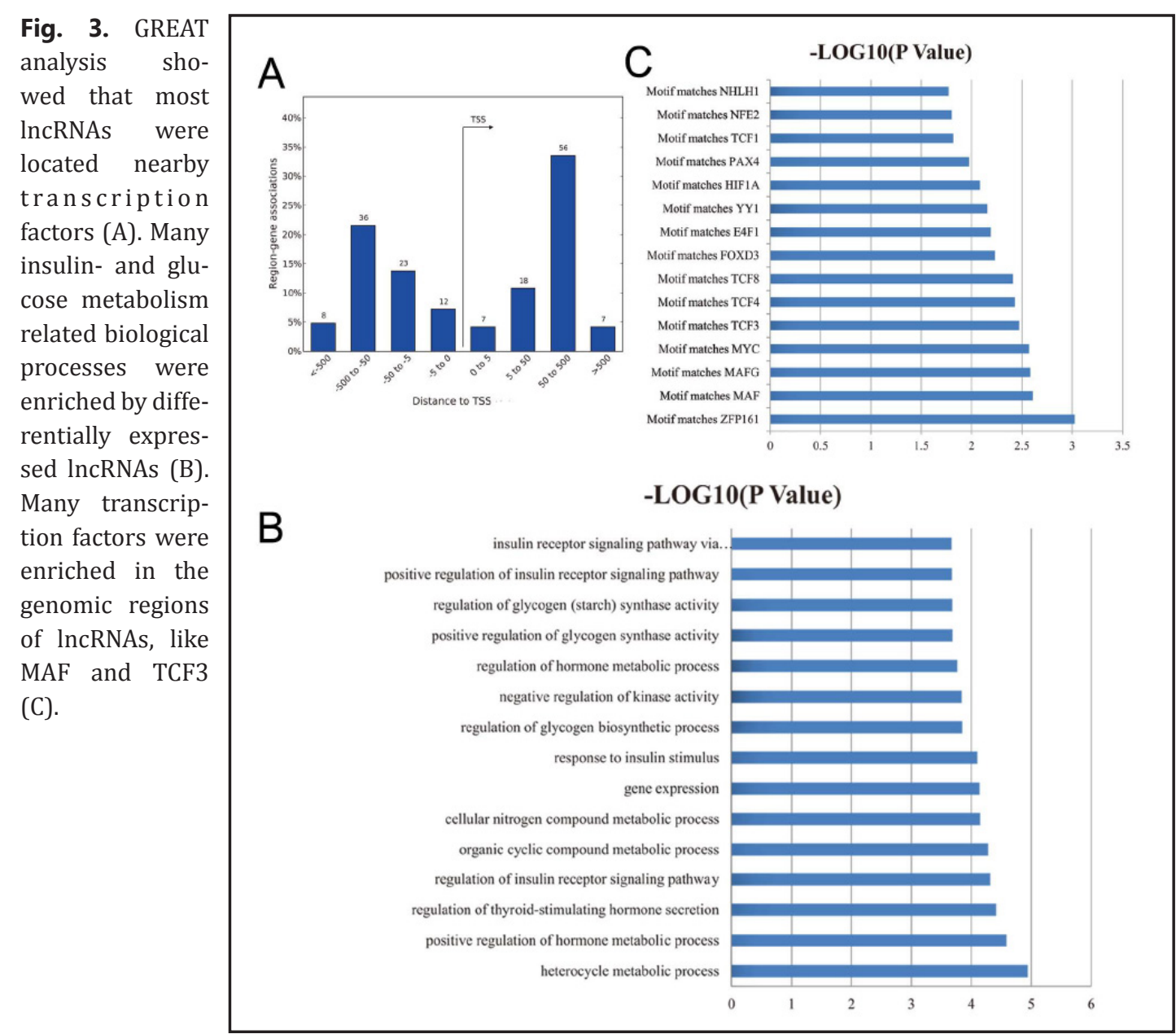

Type 2 diabetes often leads to inflammation and ulcer [29]. The vascular endothelial cells and lymphatic endothelial cells are exposed to hyperglycemia and dysfunction of endothelial cells is critical for microvascular complications of type 2 diabetes [8]. Previous studies have proved that IncRNAs are involved in the function of vascular endothelial cells and IncRNA expression changes in response to stimulus. For example, Tan Y showed that IncRNA MALAT1 MALAT1 could protects the endothelium from ox-LDL-induced endothelial dysfunction by upregulating CXCR2 [30]. In this study, we found many lncRNAs were differentially expressed in diabetic lymphatic endothelial cells, including several wellknown lncRNAs, like CRNDE, H19, and GAS5. H19 was the most down-regulated lncRNA and it has been reported H19 is closely related with diabetes [20]. In this study, we found IncRNA and mRNA were co-expressed in lymphatic endothelial cells and these IncRNAs are highly possible involved in the dysfunction of lymphatic endothelial cells. Additionally, coexpressed network indicated 4 lncRNAs have highest degrees and are the center of network, suggesting they may play central roles. Further experiments are needed to clarify biological functions of these lncRNAs.

To probe the biological function of these differentially expressed lncRNA, GREAT analysis was performed. GREAT analysis refers function of non-coding RNAs based on cis regulation [19]. GREAT showed these IncRNAs were enriched in the biological function related with type 2 diabetes, like regulation of insulin pathways and response to insulin stimulus. MAF and TCF3 are critical regulators in type2 diabetes and many MAF-regualted genes are involved in the pathogenesis of type 2 diabetes. GREAT analysis showed MAF and TCF3 were significantly enriched in these genomic regions, indicating these lncRNAs may 


\section{Cellular Physiology Cell Physiol Biochem 2017;41:466-474

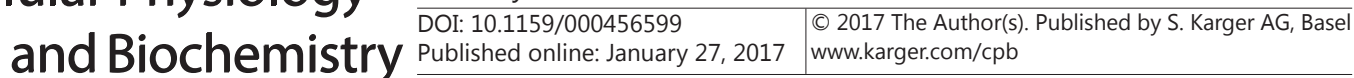 \\ Qi et al.: IncRNA in Lymphatic Endothelial Cells}

be regualted by these TCs. On the other hand, further experiments are needed to validate bioinformatics prediction.

In the current study, we analyzed lncRNA expression of lymphatic endothelial cells in diabetic and non-diabetic patients and this study provides insights into the important roles of lncRNA in lymphatic endothelial cells.

\section{Acknowledgement}

This study was supported by grant No.81301986 (Min Qi) and 81472852 (Jianglin Zhang) from the National Natural Science Foundation of China.

\section{Disclosure Statement}

The authors declare no conflict of interest.

\section{References}

1 Wild S, Roglic G, Green A, Sicree R, King H: Global prevalence of diabetes: estimates for the year 2000 and projections for 2030. Diabetes Care 2004,27:1047-1053.

-2 Dong Y, Wu Y, Choi HC, Wang S: Diabetic Endothelium Dysfunction, Cardiovascular Complications, and Therapeutics. J Diabetes Res 2016,2016:5349801.

-3 Deanfield JE, Halcox JP, Rabelink TJ: Endothelial function and dysfunction: testing and clinical relevance. Circulation 2007,115:1285-1295.

-4 Sena CM, Pereira AM, Seica R: Endothelial dysfunction - a major mediator of diabetic vascular disease. Biochim Biophys Acta 2013,1832:2216-2231.

\$ Calcutt NA, Cooper ME, Kern TS, Schmidt AM: Therapies for hyperglycaemia-induced diabetic complications: from animal models to clinical trials. Nat Rev Drug Discov 2009,8:417-429.

6 Wang Y, Oliver G: Current views on the function of the lymphatic vasculature in health and disease. Genes Dev 2010,24:2115-2126.

7 Harrison DG: Cellular and molecular mechanisms of endothelial cell dysfunction. J Clin Invest 1997,100:2153-2157.

8 Jansson PA: Endothelial dysfunction in insulin resistance and type 2 diabetes. J Intern Med 2007,262:173183.

-9 Ponting CP, Oliver PL, Reik W: Evolution and functions of long noncoding RNAs. Cell 2009,136:629-641.

10 Uchida S, Dimmeler S: Long noncoding RNAs in cardiovascular diseases. Circ Res 2015,116:737-750.

-11 Voellenkle C, Garcia-Manteiga JM, Pedrotti S, Perfetti A, De Toma I, Da Silva D, Maimone B, Greco S, Fasanaro P, Creo P, Zaccagnini G, Gaetano C, Martelli F: Implication of Long noncoding RNAs in the endothelial cell response to hypoxia revealed by RNA-sequencing. Sci Rep 2016,6:24141.

-12 Murakami K: Non-coding RNAs and hypertension-unveiling unexpected mechanisms of hypertension by the dark matter of the genome. Curr Hypertens Rev 2015,11:80-90.

13 Michalik KM, You X, Manavski Y, Doddaballapur A, Zornig M, Braun T, John D, Ponomareva Y, Chen W, Uchida S, Boon RA, Dimmeler S: Long noncoding RNA MALAT1 regulates endothelial cell function and vessel growth. Circ Res 2014,114:1389-1397.

14 Cheng HS, Njock MS, Khyzha N, Dang LT, Fish JE: Noncoding RNAs regulate NF-kappaB signaling to modulate blood vessel inflammation. Front Genet 2014,5:422.

15 Yin DD, Zhang EB, You LH, Wang N, Wang LT, Jin FY, Zhu YN, Cao LH, Yuan QX, De W, Tang W: Downregulation of IncRNA TUG1 affects apoptosis and insulin secretion in mouse pancreatic beta cells. Cell Physiol Biochem 2015,35:1892-1904. 


\section{Cellular Physiology Cell Physiol Biochem 2017;41:466-474

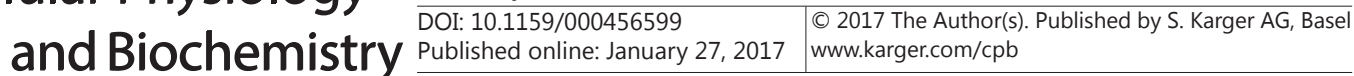 \\ Qi et al.: IncRNA in Lymphatic Endothelial Cells}

16 Shi Z, Zhao C, Long W, Ding H, Shen R: Microarray Expression Profile Analysis of Long Non-Coding RNAs in Umbilical Cord Plasma Reveals their Potential Role in Gestational Diabetes-Induced Macrosomia. Cell Physiol Biochem 2015,36:542-554.

17 Haemmerle M, Keller T, Egger G, Schachner H, Steiner CW, Stokic D, Neumayer C, Brown MK, Kerjaschki D, Hantusch B: Enhanced lymph vessel density, remodeling, and inflammation are reflected by gene expression signatures in dermal lymphatic endothelial cells in type 2 diabetes. Diabetes 2013,62:25092529.

18 Zhang X, Sun S, Pu JK, Tsang AC, Lee D, Man VO, Lui WM, Wong ST, Leung GK: Long non-coding RNA expression profiles predict clinical phenotypes in glioma. Neurobiol Dis 2012,48:1-8.

19 McLean CY, Bristor D, Hiller M, Clarke SL, Schaar BT, Lowe CB, Wenger AM, Bejerano G: GREAT improves functional interpretation of cis-regulatory regions. Nat Biotechnol 2010,28:495-501.

20 Gao Y, Wu F, Zhou J, Yan L, Jurczak MJ, Lee HY, Yang L, Mueller M, Zhou XB, Dandolo L, Szendroedi J, Roden M, Flannery C, Taylor H, Carmichael GG, Shulman GI, Huang Y: The H19/let-7 double-negative feedback loop contributes to glucose metabolism in muscle cells. Nucleic Acids Res 2014,42:13799-13811.

-21 Moon HS, Dincer F, Mantzoros CS: Pharmacological concentrations of irisin increase cell proliferation without influencing markers of neurite outgrowth and synaptogenesis in mouse H19-7 hippocampal cell lines. Metabolism 2013,62:1131-1136.

22 Ding GL, Wang FF, Shu J, Tian S, Jiang Y, Zhang D, Wang N, Luo Q Zhang Y, Jin F, Leung PC, Sheng JZ, Huang HF: Transgenerational glucose intolerance with Igf2/H19 epigenetic alterations in mouse islet induced by intrauterine hyperglycemia. Diabetes 2012,61:1133-1142.

23 Kaneto H, Matsuoka TA: Role of pancreatic transcription factors in maintenance of mature beta-cell function. Int J Mol Sci 2015,16:6281-6297.

24 Kannan MB, Solovieva V, Blank V: The small MAF transcription factors MAFF, MAFG and MAFK: current knowledge and perspectives. Biochim Biophys Acta 2012,1823:1841-1846.

-25 Esteller M: Non-coding RNAs in human disease. Nat Rev Genet 2011,12:861-874.

26 Mercer TR, Dinger ME, Mattick JS: Long non-coding RNAs: insights into functions. Nat Rev Genet 2009,10:155-159.

27 Qiu M, Feng D, Zhang H, Xia W, Xu Y, Wang J, Dong G, Zhang Y, Yin R, Xu L: Comprehensive analysis of lncRNA expression profiles and identification of functional lncRNAs in lung adenocarcinoma. Oncotarget 2016;7:16012-16022.

28 Hu Y, Chen HY, Yu CY, Xu J, Wang JL, Qian J, Zhang X, Fang JY: A long non-coding RNA signature to improve prognosis prediction of colorectal cancer. Oncotarget 2014,5:2230-2242.

29 Van Hattem S, Bootsma AH, Thio HB: Skin manifestations of diabetes. Cleve Clin J Med 2008,75:772, 774, 776-777 passim.

30 Tang Y, Jin X, Xiang Y, Chen Y, Shen CX, Zhang YC, Li YG: The IncRNA MALAT1 protects the endothelium against ox-LDL-induced dysfunction via upregulating the expression of the miR-22-3p target genes CXCR2 and AKT. FEBS Lett 2015,589:3189-3196. 